\title{
Study the Efficacy of Pseudomonas fluorescens against Sheath Blight in Rice by Rhizoctonia solani
}

\author{
Biyyani Suman*, A. VijayaGopal, R. Subhash Reddy, S. Triveni and M. Nissipaul \\ Department of Agricultural Microbiology and Bioenergy, College of Agriculture, \\ Professor Jayashankar Telangana State Agricultural University (PJTSAU), \\ Rajendranagar, Hyderabad, India \\ *Corresponding author
}

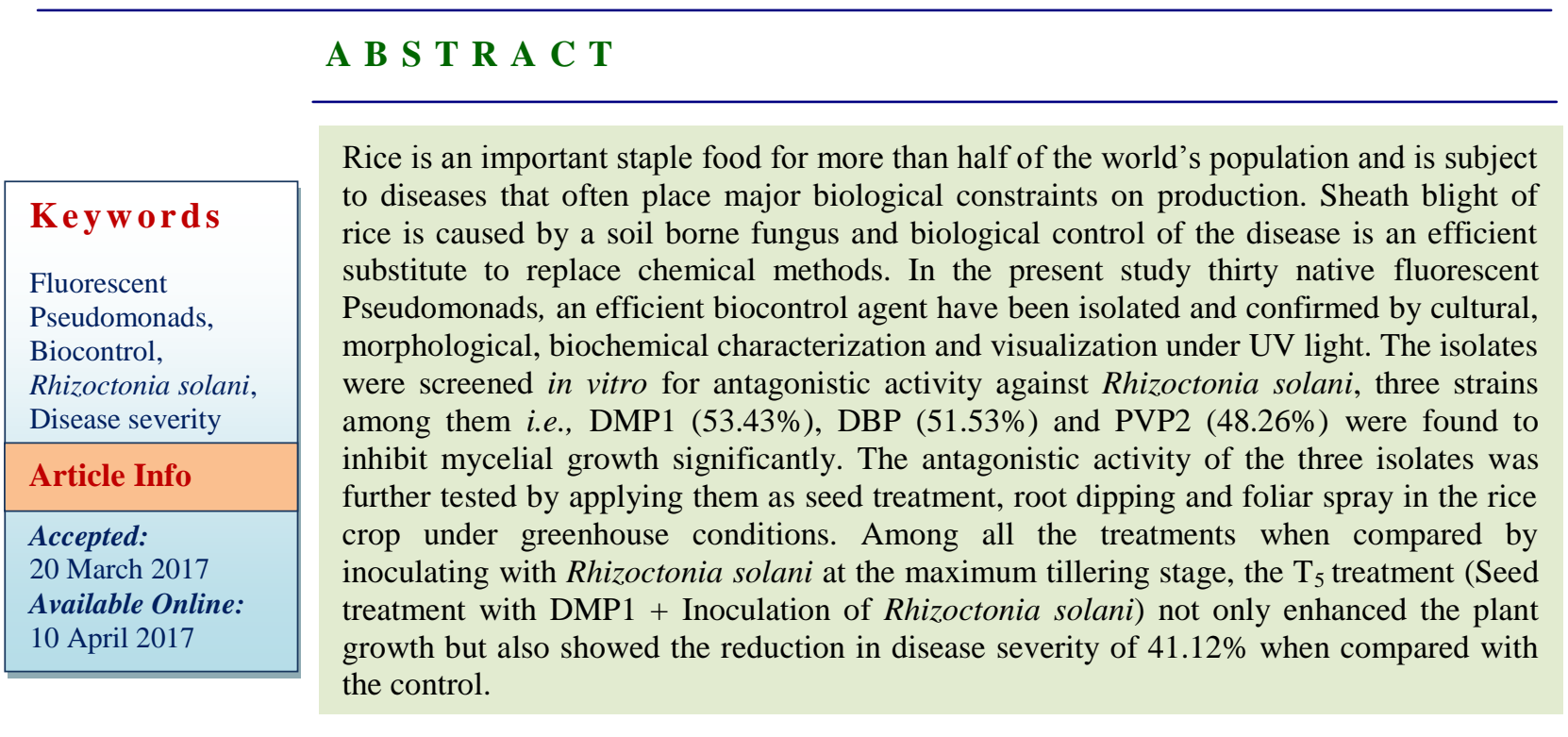

\section{Introduction}

Rice (Oryza sativa) is India's pre-eminent crop, it is the most widely consumed staple food for a large part of the world's human population, especially in Asia. Moreover, the country has the biggest area under rice cultivation, as it is one of the principal food crops. India is one of the leading producers of this crop, with a production, productivity of 105.48 million tons and $2391 \mathrm{~kg}$ per hectare respectively (Indiastat, 2014-15).

Sheath blight caused by a soil borne fungus (Rhizoctonia solani), is considered to be the most economically significant fungal rice disease in the world (Groth et al., 1988). Both local and high yielding varieties are susceptible to this disease (Naidu, 1989). The pathogen attacks the rice plant at maximum tillering stage by sclerotium, the primary source of inoculum that over winter in soil and plant debris (Ou, 1985). Yield loss can occur at any stage but is higher when infection occurs at panicle initiation, booting and flowering (Sharma et al., 1990). Sheath blight also interferes with grain filling (Marchetti, 1983) and can reduce rice yield by 
$39 \%$, but that loss can increase to $50 \%$ in terms of $\mathrm{kg} / \mathrm{ha}$ of milled whole grain rice because grains can be weakened and subsequently break during milling. A possibility of $46 \%$ yield loss in milled rice has been estimated if sheath blight lesions reach 90\% of the plant height (Ahn and Mew, 1986).

The disease is alarming due to its intensive cultivation of modern high yielding varieties with high doses of nitrogenous fertilizers. Crop with a high plant density and close canopy favours disease build up from panicle initiation onwards. Poor weed management practices and increase in frequency of irrigation have aggravated, incidence of the disease due to modified micro climatic conditions (Srinivas et al., 2013).

The use of chemical fertilizers and pesticides caused an incredible harm to the environment. These agents are both hazardous and may persist and accumulate in natural ecosystems an answer to this problem is replacing chemicals with biological approaches, which are considered more environment friendly in the long term. One of the emerging research area for the control of different phytopathogenic agents is the use of biocontrol plant growth promoting rhizobacteria (PGPR), which are capable of suppressing or preventing the phytopathogen damage (Nihorembere et al., 2011).

Beneficial rhizobacteria that stimulate plant growth are usually referred as plant growth promoting rhizobacteria (PGPR). PGPR are heterogeneous group of bacteria that can be found in the rhizosphere, at root surfaces and in association with roots. They can improve the extent or quality of plant growth by direct or indirect methods. In last few decades, a large array of bacteria have been isolated and reported to enhance plant growth (Glick, 1995). The contributions of PGPR were emphasized clearly for safe and sustainable agriculture development (Singh et al., 2011).

Pseudomonas fluorescens encompasses a group of common, non-pathogenic saprophytes that colonize soil, water and plant surface environments. Several strains of $P$. fluorescens have been successfully used for the biological control of rice sheath blight (Rabindran and Vidhyasekaran, 1996).Their applicability as biocontrol agents has drawn wide attention because of the production of secondary metabolites such as siderophores, antibiotics, volatile compounds, $\mathrm{HCN}$, enzymes and phytohormones (Gupta et al., 2001). They can be utilized in low input sustainable agricultural applications, such as biocontrol, on account of their ability to synthesize secondary metabolites with antibiotic properties and many of such antibiotics produced have a broad spectrum activity but strain to strain variations do exist (Raaijimakers et al., 2002). These secondary metabolites include 2,4diacetylphloroglucinol (DAPG), phenazine (Phz), pyrrolnitrin, oomycin A, viscosinamide, pyoluteorin and hydrogen cyanide $(\mathrm{HCN})$.

In the present study keeping in view the importance of Pseudomonas fluorescens as biocontrol agents they have been successfully isolated and used as seed treatment, foliar spray and root dipping for the control of Sheath blight in rice.

\section{Materials and Methods}

\section{Soil sampling}

Soil samples were collected from twenty two villages of Rangareddy district for the isolation of Pseudomonas fluorescens strains. The samples were collected from rice rhizosphere. Crop plants were selected randomly in the field and the intact root 
system was dug out, carefully taken in plastic bags, labelled well and stored at $4^{0} \mathrm{C}$.

\section{Isolation}

King's B selective medium was used for the isolation of $P$. fluorescens (King's et al., 1954).

Preparation of inoculum of Rhizoctonia solani

Three hundred grams of sterilized barley seed was placed in Erlenmeyer flask, then each flask was inoculated with $5 \mathrm{~mm}$ mycelial disc from a 4 days old culture of Rhizoctonia solani grown on PDA was placed in the flasks and they were incubated at room temperature $\left(26 \pm 2^{0} \mathrm{C}\right)$ for 3 weeks (Kazempour, 2004).

Inoculation of Rhizoctonia solaniin the rice crop

At the maximum tillering stage the pathogen was inoculated into the crop by placing the barley grains with mycelia at the centre of the hill above the ground level (Singh and Sinha, 2005).

\section{Percent germination}

Seed germination of the Pseudomonas fluorescens treated seeds was determined by the standard roll towel method (International Seed Testing Association, 1996).

Methods of application of Pseudomonas fluorescens

\section{Seed treatment}

Rice seeds were surface sterilized with $2 \%$ Sodium hypochlorite solution and soaked in a double volume of bacterial suspension

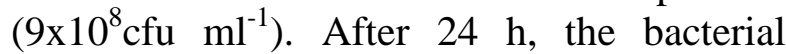
suspension was drained and the seeds were dried under shade for $30 \mathrm{~min}$. The seeds were allowed to sprout for another $24 \mathrm{~h}$ before sowing (Vidhyasekaran et al., 1997). After 25 days, the seedlings were pulled out from the pots and transplanted at the rate of four seedlings per hill and two hills per pot $(30 \mathrm{~cm}$ diameter containing $10 \mathrm{~kg}$ of clay soil).

\section{Root dipping}

Rice seedling in bundles (approximately 200 seedlings) were dipped in $250 \mathrm{ml}$ of bacterial suspension $\left(9 \times 10^{8} \mathrm{cfu} \mathrm{ml}^{-1}\right)$ for $2 \mathrm{~h}$, ensuring that roots alone were immersed in the inoculum and planted in pots.

\section{Foliar application}

$25 \mathrm{ml}$ of bacterial suspension $\left(9 \times 10^{8} \mathrm{cfu} \mathrm{ml}^{-1}\right)$ per pot was sprayed 30 days after transplanting (Vidhyasekaran et al., 1997).

\section{Growth characteristics}

\section{Plant height}

The plant height was recorded by measuring the total height from the base of the plant to the tip of the plant at 30,60 and 90 DAT and is expressed in centimeters.

\section{Total number of tillers hill ${ }^{-1}$}

In each pot the number of tillers were counted on each plant at 30,60 and 90 DAT and expressed as total number of tillers hill ${ }^{-1}$.

\section{Number of productive tillers hill ${ }^{-1}$}

The ear bearing tillers, which produced healthy panicles were counted and expressed as number of productive tillers hill ${ }^{-1}$.

\section{Measurement of chlorophyll content} (SCMR Values)

The SPAD-502 (Soil plant analytical development) was used for measuring the 
relative chlorophyll content of leaves at 30 , 60 and 90 DAT.

The chlorophyll content was measured for recent fully expanded leaves. Mean of the five values from each hill was obtained. This meter enables obtaining instant readings without destroying the plant tissue.

\section{Reduction in disease severity}

Development of symptoms was observed and recorded 7 days after inoculation as grades $0 \pm 9$ (IRRI, 2002). Based on the grades, the disease index was calculated using the following formula

Disease index $=$ Total grade $/$ No. of sheath observed x $100 /$ maximum grade

\section{Statistical analysis}

The data obtained in the experiment was statistically analyzed using Completely Randomized Design (CRD) as per the procedures given by Snedecor and Cochran (1967) and Panse and Sukhatme (1985).

Data on different characters viz., growth components, PDI and reduction in disease severity, were subjected to analysis of variance procedures as outlined for CRD.

Statistical significance was tested by $\mathrm{F}$-value at 0.05 level of probability and critical difference was worked out where ever the effects were significant.

\section{Results and Discussion}

The experiment was conducted during Rabi, 2014-15 with Completely Randomized Design, in the green house, College of Agriculture, Rajendranagar, Hyderabad and the results are presented and discussed here under various headings.
Screening and selection of Pseudomonas fluorescens isolates

Thirty Pseudomonas fluorescens isolates were isolated from the soil samples using King's B agar and they were confirmed by cultural, morphological, biochemical characterization and visualization under UV light. The isolates were further studied for the PGPR attributes and found positive for either of them.

In the preliminary screening of $30 \quad P$. fluorescens isolates for antagonistic activity against Rhizoctonia solani under in vitro conditions, three strains DMP1 (53.43\%), DBP (51.53\%) and PVP2 (48.26\%) were found efficient to inhibit mycelial growth when compared with other strains and these strains were further used for pot culture study.

Influence of Pseudomona fluorescens on growth parameters of rice

\section{Percent germination}

The effect of DBP, DMP1 and PVP2 on germination of rice was conducted on standard roll towel. The results showed that highest percent germination was found with the seeds inoculated with PVP2 i.e., 100\% followed by DBP (98.35\%) when compared with the control (90\%) (Table 1).

The isolates obtained in our study when seed treated with the rice grains enhanced germination percentage. Pseudomonas fluorescens is one among the PGPR having the ability to produce plant growth regulators such as gibberlins, cytokinins and indole acetic acid etc. which induced higher percentage of germination in the seeds when compared with the untreated control.

\section{Plant height}

Plant heights at 30, 60 and 90 DAT are measured and the values are mentioned in 
Table 2. Plant height at 30 DAT was found significantly highest in $\mathrm{T}_{5}$ (Seed treatment with DMP1 +Inoculation of Rhizoctonia solani) i.e., $56 \mathrm{~cm}$ followed by $52 \mathrm{~cm}$ with $\mathrm{T}_{6}$ (Root dipping with DMP1 +Inoculation of Rhizoctonia solani)and least was found with control ( $\mathrm{T}_{1}$ : Inoculation of Rhizoctonia solanialone) i.e., $42 \mathrm{~cm}$.

Plant height at 60 DAT was found highest in $\mathrm{T}_{5}$ (Seed treatment with DMP1 + Inoculation of Rhizoctonia solani) $74 \mathrm{~cm}$ on par with 72 $\mathrm{cm}$ i.e., $\mathrm{T}_{8}$ (Seed treatment with $\mathrm{DBP}+$ Inoculation of Rhizoctonia solani) and $\mathrm{T}_{2}$ (seed treatment with PVP2 + Inoculation of Rhizoctonia solani) and least was found with control $\left(\mathrm{T}_{1}\right.$ : Inoculation of Rhizoctonia solanialone) i.e., $57.3 \mathrm{~cm}$.

Plant height at 90 DAT was found highest in $\mathrm{T}_{5}$ (Seed treatment with DMP1 + Inoculation of Rhizoctonia solani) $82.6 \mathrm{~cm}$ found on par with $\mathrm{T}_{8}$ (Seed treatment with $\mathrm{DBP}+$ Inoculation of Rhizoctonia solani) $82.1 \mathrm{~cm}$ and least was found with control $\left(\mathrm{T}_{1}\right.$ : Inoculation of Rhizoctonia solani alone) i.e., $68.2 \mathrm{~cm}$.

Seed treatment, root dipping and foliar application with plant growth promoting rhizobacterial bioformulations significantly enhanced the growth of rice plants compared with the control. Seed treatment had shown effective growth with the organisms DMP1, DBP and PVP2 when compared with root dipping and foliar spray as the inocula to rest of them has been added at later stage.

When the strains are considered, $\mathrm{T}_{5}$ i.e., Seed treatment with DMP1 had shown best plant growth promotion as it is having the ability to produce siderophores, IAA, Ammonia and $\mathrm{HCN}$ followed by $\mathrm{T}_{8}$ i.e., seed treatment with DBP having IAA, ammonia and $\mathrm{HCN}$ producing ability.

\section{Number of tillers per plant}

Number of tillers at 30 DAT was found significantly highest with the treatment $\mathrm{T}_{5}$ (Seed treatment with DMP1 + Inoculation of Rhizoctonia solani) i.e., 13.7 followed by 12.3 with $\mathrm{T}_{6}$ (Root dipping with DMP1 +Inoculation of Rhizoctonia solani), and the least was found with control $\left(\mathrm{T}_{1}\right.$ : Inoculation of Rhizoctonia solani alone) i.e., 8.3.

Number of tillers at 60 DAT was found significantly highest with the treatment $T_{5}$ (Seed treatment with DMP1 + Inoculation of Rhizoctonia solani) i.e., 17.3 next to it is 16.0 with $\mathrm{T}_{6}$ (Root dipping with DMP1 +Inoculation of Rhizoctonia solani) and least was found with control $\left(\mathrm{T}_{1}\right.$ : Inoculation of Rhizoctonia solani alone) 11.3.

Number of tillers at 90 DAT was found significantly highest with the treatment $\mathrm{T}_{5}$ (Seed treatment with DMP1 + Inoculation of Rhizoctonia solani) i.e., 17.3 followed by 14.7 with $\mathrm{T}_{8}$ (Seed treatment with $\mathrm{DBP}+$ Inoculation of Rhizoctonia solani) and least was found with control $\left(\mathrm{T}_{1}\right.$ : Inoculation of Rhizoctonia solani alone) 11.3 (Table 2).

In our study along with the inhibition of Rhizoctonia solani, seed treated plants have shown good plant growth promoting traits compared with the root dipped and foliar sprayed plants. Besides plant height, increase in the number of tillers was reported in the rice plants treated with the plant growth promoting rhizobacteria (Salamone et al., 2012).

\section{Number of panicles per plant}

Number of panicles at 90 DAT was found highest i.e., 13.7 with the treatment $\mathrm{T}_{5}$ (Seed treatment with DMP1 + Inoculation of Rhizoctonia solani) followed by $\mathrm{T}_{8}$ (Seed treatment with DBP + Inoculation of 
Rhizoctonia solani) 13.3 and least was found with control $\left(\mathrm{T}_{1}\right.$ : Inoculation of Rhizoctonia solani alone) 8.7 (Table 2).

\section{Chlorophyll content}

Chlorophyll content with SPAD meter was measured at 30, 60 and 90 DAT (Table 2). Chlorophyll content at 30 DAT was found highest with the treatment $\mathrm{T}_{5}$ (Seed treatment with DMP1 + Inoculation of Rhizoctonia solani) 39.6 and least was found with control ( $\mathrm{T}_{1}$ : Inoculation of Rhizoctonia solani alone) i.e., 32.7. Chlorophyll content at 60 DAT was found highest with the treatment $\mathrm{T}_{5}$ (Seed treatment with DMP1 + Inoculation of Rhizoctonia solani) 48.17 and least was found with control $\left(\mathrm{T}_{1}\right.$ : Inoculation of Rhizoctonia solani alone) i.e., 40.60. Chlorophyll content at 90 DAT was found highest with the treatment $\mathrm{T}_{5}$ (Seed treatment with DMP1 + Inoculation of Rhizoctonia solani) i.e.,42.13 followed by $\mathrm{T}_{8}$ (Seed treatment with DBP + Inoculation of Rhizoctonia solani) i.e., 40.15 and least was found with control $\left(\mathrm{T}_{1}\right.$ : Inoculation of Rhizoctonia solanialone) i.e., 23.78 (Table 2).

Table.1 Percent germination of Pseudomonas fluorescens strains treated seeds

\begin{tabular}{|c|c|}
\hline Organism/strain & Percent germination \\
\hline Control & 90 \\
\hline DBP & 98.35 \\
\hline DMP1 & 96.65 \\
\hline PVP2 & 100 \\
\hline CD & $\mathbf{0 . 7 8 1}$ \\
\hline SE $( \pm \mathbf{m})$ & $\mathbf{0 . 2 3 6}$ \\
\hline
\end{tabular}

Treatments

$\mathbf{T}_{1}$ : Inoculation of Rhizoctonia solanialone

$\mathbf{T}_{2}$ : Seed treatment with PVP2 + Inoculation of Rhizoctonia solani

$\mathbf{T}_{\mathbf{3}}$ : Root dipping with PVP2 + Inoculation of Rhizoctonia solani

$\mathbf{T}_{4}$ : Foliar spray with PVP2 +Inoculation of Rhizoctonia solani

$\mathbf{T}_{5}$ : Seed treatment with DMP1 + Inoculation of Rhizoctonia solani

$\mathbf{T}_{\mathbf{6}}$ : Root dipping with DMP1 + Inoculation of Rhizoctonia solani

$\mathbf{T}_{7}$ : Foliar spray with DMP1 + Inoculation of Rhizoctonia solani

$\mathbf{T}_{\mathbf{8}}$ : Seed treatment with DBP + Inoculation of Rhizoctonia solani

T9: Root dipping with DBP + Inoculation of Rhizoctonia solani

$\mathbf{T}_{\mathbf{1 0}}$ : Foliar spray with DBP +Inoculation of Rhizoctonia solani 
Table.2 Influence of Pseudomonas fluorescens on growth parameters of rice, PDI and Percent reduction of the disease

\begin{tabular}{|c|c|c|c|c|c|c|c|c|c|c|c|c|}
\hline \multirow{2}{*}{ Treatments } & \multicolumn{3}{|c|}{ Plant height(cm) } & \multicolumn{3}{|c|}{ Number of tillers plant ${ }^{-1}$} & \multirow{2}{*}{$\begin{array}{c}\begin{array}{c}\text { No. of } \\
\text { panicles }\end{array} \\
90 \text { DAT }\end{array}$} & \multicolumn{3}{|c|}{ Chlorophyll content } & \multirow{2}{*}{ PDI } & \multirow{2}{*}{$\begin{array}{c}\text { Reduction } \\
\text { in disease } \\
\text { severity }\end{array}$} \\
\hline & 30 DAT & 60 DAT & 90 DAT & 30 DAT & $60 \mathrm{DAT}$ & 90 DAT & & 30 DAT & 60 DAT & $\begin{array}{c}90 \\
\text { DAT }\end{array}$ & & \\
\hline $\mathbf{T}_{1}$ & 42.00 & 57.30 & 68.20 & 8.3 & 11.3 & 11.3 & 8.7 & 32.70 & 40.60 & 23.78 & 62.33 & 0.00 \\
\hline $\mathbf{T}_{2}$ & 51.33 & 72.00 & 78.30 & 10.3 & 14.0 & 13.7 & 12.7 & 36.07 & 45.70 & 35.27 & 44.36 & 28.84 \\
\hline $\mathbf{T}_{3}$ & 47.67 & 70.00 & 75.40 & 9.7 & 13.3 & 13.3 & 10.3 & 35.40 & 44.50 & 29.32 & 52.74 & 15.39 \\
\hline $\mathbf{T}_{4}$ & 45.67 & 59.70 & 73.30 & 9.3 & 12.7 & 12.0 & 9.7 & 34.53 & 42.57 & 27.39 & 57.25 & 8.16 \\
\hline $\mathbf{T}_{5}$ & 56.00 & 74.00 & 82.60 & 13.7 & 17.3 & 17.3 & 13.7 & 39.60 & 48.17 & 42.13 & 36.70 & 41.12 \\
\hline $\mathbf{T}_{6}$ & 52.00 & 70.70 & 78.90 & 12.3 & 16.0 & 14.3 & 12.7 & 39.40 & 47.87 & 37.13 & 43.34 & 30.47 \\
\hline $\mathbf{T}_{7}$ & 42.33 & 64.00 & 75.60 & 10.3 & 14.3 & 13.7 & 12.0 & 36.63 & 47.50 & 30.79 & 53.08 & 14.85 \\
\hline $\mathbf{T}_{8}$ & 51.67 & 72.00 & 82.10 & 11.0 & 15.0 & 14.7 & 13.3 & 37.87 & 47.43 & 40.15 & 43.38 & 30.41 \\
\hline $\mathbf{T}_{9}$ & 48.00 & 63.00 & 78.00 & 10.7 & 13.7 & 13.3 & 11.3 & 37.13 & 46.60 & 33.29 & 46.57 & 25.29 \\
\hline $\mathbf{T}_{10}$ & 45.67 & 61.00 & 69.30 & 10.3 & 12.7 & 12.3 & 9.7 & 33.33 & 44.23 & 25.77 & 59.71 & 4.21 \\
\hline CD & 3.525 & 2.236 & 1.250 & 0.939 & 1.129 & 1.129 & 0.939 & 2.596 & 2.998 & 2.705 & 3.128 & 0.578 \\
\hline $\mathbf{S E}( \pm \mathbf{m})$ & 1.187 & 0.753 & 0.421 & 0.316 & 0.380 & 0.380 & 0.316 & 0.874 & 1.009 & 0.508 & 1.053 & 0.195 \\
\hline
\end{tabular}


Chlorophyll content increased with increasing crop up to 60 DAT and then decreased. As the crop is inoculated with the Rhizoctonia solani, the fungus after inoculating damages the chlorophyll content of the crop and the result was found best with the seed treatment method with the organism DMP1, as it is showing plant growth promotion as well as disease resistance more compared with the other treatments.

\section{Percent Disease Index (PDI)}

Percent Disease Index (PDI) was calculated and found significantly highest $62.33 \%$ with the control $\left(\mathrm{T}_{1}\right.$ : Inoculation of Rhizoctonia solani alone) followed by $43.34 \%$ with T6 (Root dipping with DMP1 +Inoculation of Rhizoctonia solani) and PDI was lowest with the treatment $\mathrm{T}_{5}$ (Seed treatment with DMP1 + Inoculation of Rhizoctonia solani) $36.70 \%$ (Table 2).

In our study, application of the biocontrol agents as seed treatment reduced the PDI to a maximum extent, as the fungal pathogen Rhizoctonia solani is a soil borne and seed treatment inhibited the pathogen from the initial stages of plant growth followed by root dipping and foliar spray. In seed treatment the bacterial bioagent appeared to move from seed to roots, stems and leaves. The fluorescent Pseudomonads could be isolated from aerial parts of plants grown from seeds treated with the bacteria (Colyer and Mount, 1984).

\section{Reduction in disease severity}

Reduction in disease severity was calculated and maximum reduction in disease severity was found with the treatment $\mathrm{T}_{5}$ (Seed treatment with DMP1 + Inoculation of Rhizoctonia solani) $41.12 \%$ followed by $30.47 \%$ in $\mathrm{T}_{6}$ (Root dipping with DMP1 +Inoculation of Rhizoctonia solani) when compared with the control $\left(\mathrm{T}_{1}\right.$ : Inoculation of Rhizoctonia solani alone) (Table 2).Seed treated plants had shown more resistance towards the disease and the percent reduction of disease severity was also found highest in them.

The maximum reduction in disease severity $(67.8 \%)$ along with increase in grain yield (31.6\%) was recorded when Rhizoctonia solani was applied 7 days after application of Pfr 1 followed by Pfr 5 which resulted in 64.5 and $40.7 \%$ reduction in disease severity and incidence respectively was reported by Singh and Sinha (2009).

\section{Acknowledgments}

I humbly extend my profound gratitude to my Professors, staff Department of Agricultural Microbiology and Bioenergy, College of Agriculture, PJTSAU, Hyderabad for their constant support and valuable suggestions offered during the course of research work.

\section{References}

Ahn, S.W. and Mew, T.W. (1986). Relation between rice sheath blight (SHB) and yield. IRRN. 11, 21-22.

Colyer, P.D. and Mount, M.S. (1984). Bacterization of Potatoes with Pseudomonas putida and Its Influence on Postharvest Soft Rot diseases. Plant Disease. 68, 703-706.

Glick, B.R. (1995). The enhancement of plantgrowth by free-living bacteria. Canadian Journal of Microbiology. 41, 109-117.

Groth, D., Jones, R.K., Lee, F., Marchetti, M.A., Moore, W., Webster, R. and Whitney, G. (1988). Sheath blight. Rice J. 91, 5-11.

Gupta, C.P., Dubey, R.C., Kang, S.C. and MahehWari, D.K. (2001). Antibiosismediated necrotrophic effect of Pseudomonas GRC2 against two fungal plant pathogens. Current Science. 81, 9194.

Indiastat. (2014-2015). Agriculture production. 
$10^{\text {th }}$ june 2015. http://www.indiastat.com

International Rice Research Institute. (2002). $4^{\text {th }}$ Edition, INGER Genetic Resource Centre.

International Seed Testing Association, (1996). International rules for seed testing. Seed Science and Technology. 24.

Kazempour, M.N. (2004). Biological Control of Rhizoctonia solani the Causal Agent of Rice 0Sheath Blight by Antagonistics Bacteria in Green House and Field Conditions. Plant Pathology Journal. 3(2), 88-96.

King's, E.O., Ward, M.K. and D.E. Raney, (1954): Two simple media for the demonstration of pyocenin and fluorescin. J. Lab. Clin.Med., 44, 301-307.

Marchetti, M.A. (1983). Potential Impact of Sheath Blight on Yield and Milling Quality of Short-Statured Rice Lines in the Southern United States. Plant Disease. 67, 162-165.

Naidu, V.D. (1989). Influence of sheath blight of rice on grain and straw yield in some popular local varieties. Journal of Research, Assam Agricultural University. 10(1-2), 78-80.

Nihorembere, V., Ongena, M. and Smargiass, M. (2011). Beneficial effect of the rhizosphere microbial community for plant growth and health. Biotechnol.Agron. Soc. Environ. 15(2), 327-337.

Ou, S.H. (1985). Rice Diseases, $2^{\text {nd }}$ edn. Common wealth Mycological Institute, Surrey.

Panse, V.S. and Sukhatme, P.V. (1985). Statistical Methods for Agricultural Workers. ICAR, New Delhi. 152-155.

Raaijmakers, J.M., Vlami, M. and de Souza, J.T. (2002). Antibiotic production by bacterial biocontrol agents. Antonie Van Leeuwenhoek. 81, 537-547.

Rabindran, R and Vidhyasekaran, P. (1996). Development of a formulation of Pseudomonas fluorescens PfALR2 for management of rice sheath blight. Crop Protection. 15,715-721.

Salamone, I.E.G., Funes, J.M., Salvo, L.P., Ortega, J.E.S., D’Auria, F., Ferrando, L. and Scavino, A.F. (2012). Inoculation of paddy rice with Azospirillum brasilense and Pseudomonas fluorescens: Impact of plant genotypes on rhizosphere microbial communities and field crop production. Applied Soil Ecology. 61, 196- 204.

Sharma, N.R., Teng, P.S. and Olivares, F.M. (1990). Effect of rice growth stage on sheath blight $(\mathrm{ShB})$ development and yield loss. IRRN 15, 19-20.

Singh, J.S., Pandey, V.C. and Singh, D.P. (2011). Efficient soil microorganisms: A new dimension for sustainable agriculture and environmental development. Agriculture, Ecosystems and Environment. 140,339-353.

Singh. R. and Sinha, A.P. (2005). Management of rice sheath blight by Pseudomonas fluorescens. Annals of Plant Protection Sciences. 13(2), 410-414.

Singh. R. and Sinha, A.P. (2009). Biological control of rice sheath blight with antagonistic bacteria. Annals of Plant Protection Sciences. 17(1), 107-110.

Snedecor, G.W. and Cochron, W.G. (1967). Statistical methods. Oxford and IBH Publishing Company. New Delhi. 593.

Srinivas, P., Ratan, V., Patel, A.P. andMadhavi, G.B. (2013).Review on banded Leaf and Sheath blight of Rice caused by Rhizoctonia solani Kuhn. International Journal of Applied Biology and Pharmaceutical Technology. 4(4), 178-185.

Vidhyasekaran, P., Rabindran, R., Muthamilan, M., Nayar, K., Rajappan, K., Subramanian, N. and Vasumathi, K. (1997). Development of powder formulation of Pseudomonas fluorescens for control of rice blast. Plant Pathology. 46, 291-297.

\section{How to cite this article:}

Biyyani Suman, A. VijayaGopal, R. Subhash Reddy, S. Triveni and Nissipaul, M. 2017. Study the Efficacy of against Sheath Blight in Rice by Rhizoctonia solani. Int.J.Curr.Microbiol.App.Sci. 6(4): 2581-2589. doi: https://doi.org/10.20546/ijcmas.2017.604.300 